\title{
Manfaat Ruang Terbuka Hijau Taman Sehati Terhadap Tingkat Kenyamanan di Kecamatan Luwuk Kabupaten Banggai Provinsi Sulawesi Tengah
}

\author{
La Ode Siwi * \\ Jurusan IImu Lingkungan, Fakultas Kehutanan dan IImu Lingkungan UHO, Kampus Kemaraya Kendari, Indonesia \\ "Corresponding Author Email: laodesiwi74@yahoo.com \\ Diterima: 28 April 2020 - Disetujui: 01 Mei 2020 - Dipublikasi: 05 Mei 2020 \\ ๑ 2020 Jurusan Biologi FMIPA Universitas Halu Oleo Kendari, Indonesia.
}

\begin{abstract}
The development of the city lately has been increasingly rapid along with the increasing number of residents both indigenous and urban residents. This causes environmental problems, such as microclimate problems that can affect thermal comfort when humans are active. The impact of microclimate problems can be reduced by the presence of vegetation, especially trees. City Park is a green open space that has the main function for beauty and social interaction and reduce microclimate. The city park as one of the green open spaces also has an ecological function in providing a sense of comfort for visitors. This study aims to determine the benefits of Taman Sehati Green Open Space on the level of comfort in Luwuk District, Banggai Regency, Central Sulawesi Province. The method used is descriptive quantitative. This research was conducted in the Sehati Park in Luwuk District in July to August 2019, the instrument used in the measurement was using the HTC-2 Digital Thermo-Hydrometer. The average comfort level in Taman Sehati on the first week measurement on Monday was THI 25,95 and on Sunday the THI value was 25,79. Measurement of week II on Monday THI value of 25,43 and on Sunday the value of THI 25,74. The measurement point of week III on Monday is THI value of 24,89 and on Sunday the value of THI is 25,15 . The conclusion from this study is that the THI value in the Taman Sehati green space only in the morning the conditions are still comfortable while in the afternoon and evening it is classified as moderate. For the comfort level outside the Taman Sehati green space in the afternoon and evening it is already uncomfortable for visitors.
\end{abstract}

Keywords: Green Open Space, Sehati Park, Ecological Benefits, Comfort Index.

\begin{abstract}
Abstrak
Perkembangan kota belakangan ini sudah semakin pesat seiring bertambahnya jumlah penduduk baik penduduk asli maupun penduduk hasil urbanisasi. Hal ini menyebabkan timbul masalah lingkungan, seperti masalah iklim mikro yang dapat mempengaruhi kenyamanan termal saat manusia beraktifitas. Dampak permasalahan iklim mikro dapat dikurangi dengan adanya vegetasi terutama pohon. Taman Kota adalah adalahruang terbuka hijau yang mempunyai fungsi utama untuk keindahan dan interaksi sosial serta menurunkan iklim mikro. Taman kota sebagai salah satu ruang terbuka hijau juga memiliki fungsi ekologi dalam memberikan rasa nyaman bagi pengunjung. Penelitian ini bertujuan untuk mengetahui manfaat Ruang Terbuka Hijau Taman Sehati terhadap tingkat kenyamanan di Kecamatan Luwuk Kabupaten Banggai Provinsi Sulawesi Tengah. Metode yang digunakan yaitu deskriptif kuantitatif. Penelitian ini dilaksanakan di Taman Sehati Kecamatan Luwuk pada Bulan Juli sampai Agustus 2019, Alat yang digunakan dalam pengukuran menggunakan Digital Thermo-Hydrometer HTC-2. Tingkat kenyamanan rata-rata di Taman Sehati pada pengukuran Minggu I pada hari senin nilai THI 25,95 dan pada hari minggu nilai THI 25,79. Pengukuran minggu II pada hari senin nilai THI 25,43 dan pada hari minggu nilai THI 25,74. Titik pengukuran minggu III pada hari senin nilai $\mathrm{THI} 24,89$ dan pada hari minggu nilai $\mathrm{THI} 25,15$. Kesimpulan dari penelitian ini bahwa nilai THI di dalam RTH Taman Sehati hanya pada pagi hari kondisinya masih nyama
\end{abstract}


sedangkan pada siang hari dan sore hari sudah tergolong sedang. Untuk tingkat kenyamanan di luar RTH Taman Sehati pada siang dan sore hari sudah tidak nyaman bagi pengunjung.

Kata kunci: Ruang Terbuka Hijau, Taman Kota, Manfaat Ekologi, Indeks Kenyamanan

\section{PENDAHULUAN}

Indonesia merupakan salah satu negara di dunia yang memiliki wilayah hutan yang sangat luas. Faktanya Indonesia menjadi sorotan dunia dalam mengahadapi global warming. Walaupun presentase jumlah daratan lebih kecil dibandingkan dengan lautan, faktanya sebagian daratan di Indonesia masih didominasi oleh kawasan hutan. Namun, kondisi geografis ini tidak membuat Indonesia terbebas dari berbagai ancaman masalah lingkungan, salah satunya polusi udara. Idealnya sebuah kota memiliki ruang terbuka untuk memunuhi kebutuhan masyarakat dalam melakukan segala aktivitasnya sekaligus mengendalikan kenyamanan iklim dan keserasian estetika kota. Namun, ruang terbuka semakin menghilang keberadaannya karena terdesak oleh pembangunan gedung-gedung yang dapat mengganggu proses infiltrasi air ke dalam tanah. Berdasarkan kondisi tersebut wilayah Indonesia membutuhkan lebih banyak Ruang Terbuka Hijau (RTH) atau bisa di sebut taman kota (Efendie, 2017).

\section{Ruang Terbuka Hijau}

Ruang terbuka merupakan suatu lahan atau kawasan dimana pada lahan tersebut tidak tertutup oleh bangunan. Jenis dari ruang terbuka ini antara lain, taman kota, lapangan olahraga, jalur sepadan/pantai, area parkir, jalur transportasi/jalan, tempat bermain, lahan pertanian, hutan, danau (Danarti, 2011). Ruang terbuka merupakan wadah yang menampung aktivitas manusia dalam suatu lingkungan yang tidak mempunyai penutup dalam bentuk fisik dan tidak dapat dipisahkan dari manusia baik secara psikologis, emosional ataupun dimensional. Manusia berada dalam ruang bergerak, menghayati dan berpikir juga membuat ruang untuk dunianya (Mulyandari, 2010)

Pada dasarnya ruang terbuka hijau ini sangat penting bagi keseimbangan lingkungan di perkotaan, selain menjadi tempat bersosialisasi ruang terbuka hijau juga dapat mengurangi suhu panas, konservasi air tanah, peredam bising dan penyaring udara kotor akibat aktivitas kendaraan di kota (Wahida et al., 2018).

\section{Jenis-Jenis Ruang Terbuka Hijau}

Jenis ruang terbuka hijau terdiri dari jenis ruang terbuka hijau publik dan ruang terbuka hijau privat (UU No. 26, 2007 Tentang Penataan Ruang). Pada intinya UU penataan ruang menjelaskan bahwa yang dimaksud dengan ruang terbuka hijau (RTH) terdiri dari ruang terbuka hijau publik dan ruang terbuka hijau privat, adalah sebagai berikut:

\section{RTH Publik}

RTH publik merupakan ruang terbuka hijau yang dimiliki dan dikelola oleh pemerintah daerah yang digunakan untuk kepentingan masyarakat secara umum, sedangkan yang termasuk ruang terbuka hijau publik antara lain adalah:

- Taman kota

- Taman pemakaman umum

- Jalur hijau sepanjang sungai, jalan, dan pantai

2. RTH Privat

Ruang terbuka hijau privat antara lain berupa kebun atau halaman 
rumah/gedung milik masyarakat/swasta yang ditanami tumbuhan. Jenis RTHKP menurut (Permendagri No.1, 2007 Tentang Penataan Ruang Terbuka Hijau Kawasan Perkotaan) meliputi: taman kota, taman wisata alam, taman rekreasi, taman lingkungan perumahan dan pemukiman, taman lingkungan perkantoran dan gedung komersial, taman hutan raya, hutan kota, hutan lindung, bentang alam seperti gunung bukit lereng dan lembah, cagar alam, kebun raya, kebun binatang, pemakaman umum, lapangan olahraga, lapangan upacara, parkir terbuka, lahan pertanian perkotaan, jalur di bawah tegangan tinggi (SUTT dan SUTET), sempadan sungai, pantai, bangunan, situ dan rawa, jalur pengaman jalan, median jalan, rel keretaapi, pipa gas dan pedestrian, kawasan dan jalur hijau, daerah penyangga (buffer zone) lapangan udara dan taman atap (roof garden).

\section{Fungsi Ruang Terbuka Hijau}

Ruang terbuka hijau (RTH) berkaitan erat dengan ekologi kota. RTH merupakan bagian dari ruang kota yang belum terbangun (terbuka) yang tertutup permukaanya didominasi oleh vegetasi. Salah satu ruang terbuka adalah sebagai penyerap air permukaan. Ruang terbuka akan berfungsi secara optimal ketika tutupan di atas lahan tersebut berupa vegetasi/tanaman. Dalam konteks pembangunan kota, vegetasi dinilai memiliki banyak kegunaan dan memberikan perlindungan terhadap manusia dari kemungkinan terjadinya bencana (Rakhman, 2012).

Fungsi hijau dalam RTH kota sebagai "paru-paru kota", sebenarnya hanya merupakan salah satu aspek berlangsungnya fungsi daur ulang, antara gas karbondioksida $\left(\mathrm{CO}_{2}\right)$ dan oksigen $\left(\mathrm{O}_{2}\right)$ hasil fotosintesis khususnya pada dedaunan. Sistem tata hijau ini berfungsi semacam ventilasi udara dalam rumah/bangunan (Hakim, 1987). Lebih dari itu, masih banyak fungsi RTH termasuk fungsi estetika yang bermanfaat sebagai sumber rekreasi publik secara aktif maupun pasif, yang diwujudkan dalam sistem koridor hijau sebagaimalat pengendali tata ruang lahan dalam suatu sistem RTH kota (urban park system). RTH juga berfungsi sebagai sumber penampungan air dan pengatur iklim tropis yang terik dan peneduh (Purnomohadi, 2006)

\section{Taman Kota}

Menurut Kamus Bahasa Indonesia, taman adalah kebun yang ditanami dengan bunga-bunga (tempat bersenang-senang) atau tempat yang menyenangkan. Taman dapat diartikan sebagai tanaman yang ditanam dan ditata sedemikian rupa, baik sebagian maupun semuanya hasil rekayasa manusia untuk mendapatkan komposisi tertentu yang indah. Menurut Arifin (1991), taman kota merupakan salah satu kawasan ruang terbuka hijau lengkap dengan segala fasilitasnya sesuai untuk pemenuhan kebutuhan rekreasi masyarakat setempat, baik rekreasi aktif maupun pasif. Taman Kota menurut Peraturan Menteri Pekerjaan Umum Nomor 5 Tahun 2008 adalah lahan terbuka yang berfungsi sosial dan estetika sebagai sarana kegiatan rekreatif, edukasi atau kegiatan lain pada tingkat kota

Salah satu tipe hutan kota adalah tipe pemukiman. Hutan kota tipe pemukiman dapat berupa taman dengan komposisi tanaman pepohonan yang tinggi dikombinasikan dengan semak dan rerumputan. Taman adalah sebidang tanah terbuka dengan luasan tertentu didalamnya ditanam pepohonan, perdu, semak dan rerumputan yang dapat dikombinasikan dengan kreasilainnya. 
Pada umumnya taman dipergunakan untuk olahraga, bersantai, bermain dan sebagainya. Setiap jenis tanaman mempunyai karakteristik tersendiri baik menurut bentuk, warna, dan teksturnya (Dahlan, 1992). Solecki dan Welch (1994), juga mengemukakan bahwa taman kota dibentuk sebagai penyekat hijau untuk memisahkan berbagai penggunaan lahan dalam kota. Taman kota dapat menjadi wahana rekreasi aktif maupun pasif, memberikan kebaikan bagi lingkungan dan menjadi habitat bagi satwa liar.

Menurut Irwan (2007), taman kota adalah ruang terbuka hijau yang mempunyai fungsi utama untuk keindahan dan interaksi sosial. Taman kota sebagi salah satu ruang terbuka hijau juga memiliki fungsi, sedangkan menurut Zoer'aini (2005) fungsi taman kota yaitu, fungsi lansekap, fungsi pelestarian lingkungan, fungsi estetika. Menurut Purnomohadi (2006) fungsi taman kota yaitu, nilai edukatif, ruang kegiatan dan tempat fasilitas kota, nilai estetika, kegiatan ekonomi, dan fungsi taman kota adalah fungsi sosial, fungsi ekologi, fungsi hidorologi, fungsi kesehatan, dan fungsi estetika.

Kecamatan Luwuk yang terletak di Kabupaten Banggai Sulawesi Tengah adalah salah satu kecamatan yang memiliki perkembangan pembangunan dan laju pertumbuhan penduduk yang cukup pesat diakibatkan karena letak ibu kota Kabupaten berada di kecamatan tersebut yaitu Kota Luwuk. Kota luwuk merupakan kota yang memiliki beragam sumber daya, baik yang alami maupun binaan yang dapat dikembangkan menjadi objek dan daya tarik wisata. Salah satu dari sumber wisata diantara sumber daya wisata yang berada di Kota Luwuk adalah Taman Sehati.

Taman Sehati yang berada di Kecamatan Luwuk merupakan Taman yang belum memenuhi proposi Ruang Terbuka Hijau. Pembangunan RTH sesuai dengan syarat Peraturan tersebut bahwa setiap wilayah Kabupaten harus memenuhi syarat miniman $30 \%$ dari total luas wilayahnya, $20 \%$ wilayah publik dan $10 \%$ wilayah privat.

\section{METODE PENELITIAN}

Penelitian ini dilakukan di Kecamatan Luwuk Kabupaten Banggai Sulawesi Tengah dilaksanakan pada bulan Juli sampai Agustus 2019 dengan menggunakan metode deskriptif kuantitatif. Pengambilan sampel dilakukan pada RTH Taman Sehati berdasarkan pengukuran temperatur, kelembaban udara, dan tingkat kenyamanan yang ada di Taman Kota. Pengukuran temperatur dan kelembaban udara dilakukan 3 kali yaitu pagi hari pukul 07.00 WITA, siang hari pukul 13.00 WITA dan sore hari pukul 17.00 WITA, kemudian dibandingkan dengan daerah di luar kawasan RTH Taman Sehati yang didominasi oleh rumput, lantai beton, dan/atau aspal.

a) Suhu optimum (TI)

Suhu optimum (ideal) ditentukan dari hasil pengukuran suhu pada pagi hari (Tp) dan suhu pada siang hari (Ts) menggunakan rumus Thom (1959), dimodifikasi oleh Nieutwolt (1977) sebagai berikut:

$T I=0,2(T s+T p)+15$

Keterangan:

$\mathrm{TI} \quad$ : Suhu optimum (TI)

Ts : Suhu udara pada siang hari $\left({ }^{\circ} \mathrm{C}\right)$

$\mathrm{Tp}$ : Suhu udara pada pagi hari $\left({ }^{\circ} \mathrm{C}\right)$

b) Rata-rata suhu udara dan kelembaban udara

Data suhu udara dan kelembaban udara dihitung menggunakan rumus menurut Tyasyono (1992) dalam Choirunnisa (2016) yaitu :

Rata-rata suhu udara dengan rumus 
$T=\frac{\left(2 \times T_{07.00}+T_{13 \cdot 00}+T_{17 \cdot 00}\right)}{4}$

Keterangan:

$\mathrm{T} \quad$ : Suhu rerata $\left({ }^{\circ} \mathrm{C}\right)$

$\mathrm{T}_{07: 00} \quad$ : Suhu yang diukur pada pagi hari $\quad\left({ }^{0} \mathrm{C}\right)$

$\mathrm{T}_{13: 00} \quad$ : Suhu yang diukur pada siang hari $\left({ }^{\circ} \mathrm{C}\right)$

$\mathrm{T}_{17: 00} \quad$ : Suhu yang diukur pada sore hari $\quad\left({ }^{0} \mathrm{C}\right)$

Rata-rata kelembaban udara

$R H=\frac{\left(2 \times R H_{07 \cdot 00}+R H_{13 \cdot 00}+R H_{17 \cdot 00}\right)}{4}$

Keterangan:

$\mathrm{RH} \quad$ : Kelembaban udara rerata harian (\%)

$\mathrm{RH}_{07: 00}$ : Kelembaban udara yang diukur pada pagi hari $(\%)$

$\mathrm{RH}_{13: 00}$ : Kelembaban udara yang diukur pada siang hari $(\%)$

$\mathrm{RH}_{17: 00}$ : Kelembaban udara yang diukur pada sore hari $(\%)$

c) Tingkat kenyamanan udara

Data suhu udara dan kelembaban udara yang telah diukur akan digunakan untuk menghitung Temperature Humidity
Index (THI) menggunakan rumus dari Nieuwolt (1977) dan Emmanuel (2005) sebagai berikut :

$T H I=0.8 T+\frac{(R H \times T)}{500}$

Keterangan :

$\mathrm{T} \quad$ : Temperatur udara $\left({ }^{\circ} \mathrm{C}\right)$

$\mathrm{RH} \quad$ : Kelembaban udara (\%)

THI : Temperature Humidity Index

\section{HASIL DAN PEMBAHASAN Jenis Vegetasi di Taman Sehati}

Hasil penelitian yang dilakukan berdasarkan jenis vegetasi yang berada di Taman Sehati dengan adanya vegetasi memberikan manfaat yang sangat penting bagi masyarakat maupun RTH yang ada di sekitarnya. Jenis tanaman yang ditemukan dalam lokasi Taman Sehati berjumlah 5 jenis yaitu Palem Raja, Bambu, Tanjung, Trambesi dan Pucuk Merah sebagaimana disajikan pada Tabel 1

Tabel 1. Jenis vegetasi di RTH Taman Sehati

\begin{tabular}{llcl}
\hline $\begin{array}{c}\text { Jenis } \\
\text { tanaman }\end{array}$ & Nama Latin & $\begin{array}{c}\text { Jumlah } \\
\text { Individu }\end{array}$ & \multicolumn{1}{c}{ Fungsi } \\
\hline Palem raja & $\begin{array}{l}\text { Roystonea } \\
\text { regia }\end{array}$ & 34 & $\begin{array}{l}\text { Tumbuhan ini mampu menyerap polusi sehingga } \\
\text { dapat meningkatkan kualitas udara di sekitar. } \\
\text { Selain itu dapat menyerap air 10\% lebih banyak di } \\
\text { bandingkan dengan tumbuhan lain. }\end{array}$ \\
Bambu & $\begin{array}{l}\text { Bambusa } \\
\text { vulgaris }\end{array}$ & 5 & $\begin{array}{l}\text { Salah satu keunggulan bamboo sebagai tanaman } \\
\text { konservasi lingkungan adalah kemampuan dalam } \\
\text { menjaga ekosistem air. Sistem perakaran }\end{array}$ \\
& $\begin{array}{l}\text { tanaman bamboo sangat rapat. Akar-akar } \\
\text { menyebar ke segala arah, baik menyamping atau }\end{array}$ \\
pun ke dalam.
\end{tabular}

Sumber: Data Primer, 2019 
Berdasarkan tabel diatas jenis vegetasi yang ada di Taman Sehati hampir di dominasi oleh Palem raja (Roystonea regia) dan Pucuk merah (Oleina syzygium). Vegetasi yang ada di Taman Sehati juga mampu menyerap polusi sehingga dapat meningkatkan kualitas udara di sekitar. Selain itu dapat menyerap air $10 \%$ lebih banyak di bandingkan dengan tumbuhan lain dan juga memberikan keindahan. Tata letak tanaman menyebar dan mengelompok.

\section{RTH Sebagai Pengatur Iklim Mikro}

1) Rata-rata suhu optimum dan suhu udara

Berdasarkan hasil penelitian analisis suhu optimum digunakan untuk mengetahui temperatur atau suhu yang dibutuhkan tanaman untuk bertumbuh dan berkembang. Pengukuran suhu adalah dengan menghitung suhu udara rata-rata harian. Lebih jelasnya dapat dilihat pada Tabel 2.

Tabel 2. Rata-rata suhu optimum dan suhu udara di Taman Sehati

\begin{tabular}{|c|c|c|c|c|c|c|c|}
\hline \multirow{2}{*}{\multicolumn{2}{|c|}{$\begin{array}{c}\text { Waktu pengambilan } \\
\text { data }\end{array}$}} & \multicolumn{3}{|c|}{ Suhu $\left({ }^{\circ} \mathrm{C}\right)$} & \multirow{2}{*}{$\begin{array}{l}\text { Suhu Optimum } \\
\left({ }^{\circ} \mathrm{C}\right)\end{array}$} & \multirow{2}{*}{$\begin{array}{c}\text { Suhu } \\
\text { rerata }\left({ }^{\circ} \mathrm{C}\right)\end{array}$} & \multirow{2}{*}{ Kriteria indeks } \\
\hline & & pagi & siang & Sore & & & \\
\hline \multirow{2}{*}{ Minggu I } & Senin & 26,5 & 29,5 & 28,7 & 26,2 & 27,8 & Agak panas \\
\hline & $\mathrm{Mi}$ & 26,8 & 28,7 & 27 & & & $\mathrm{Ag}$ \\
\hline \multirow{2}{*}{ Minggu II } & se & 25,5 & 29,3 & 28 & 25 & 27,07 & Sejuk \\
\hline & gu & 24,2 & 28 & 27 & 25 & 26,07 & Sejuk \\
\hline \multirow{2}{*}{ Minggu III } & Senin & 25,2 & 28,4 & 27,2 & 25,72 & 26,5 & Sejuk \\
\hline & Minggu & 26,4 & 28,1 & 27,3 & 25,9 & 27,05 & Sejuk \\
\hline
\end{tabular}

Sumber: Data Primer, 2019

Pada tabel 2 dapat dilihat suhu optimum tertinggi terdapat pada hari senin yaitu $26,2^{\circ} \mathrm{C}$ dan pada suhu optimum terendah terdapat pada hari senin $25,9^{\circ} \mathrm{C}$. Pada pengukuran suhu rerata tertinggi pada hari senin yaitu $27,8^{\circ} \mathrm{C}$ dengan kriteria indeks agak panas dan suhu rerata terendah pada hari senin yaitu $26,5^{\circ} \mathrm{C}$ dengan kriteria indeks sejuk. Penentuan kategori sangat dingin, dingin, agak dingin, sejuk, agak panas, panas dan sangat panas mengacu pada kriteria indeks suhu udara.

2) Indeks Kelembaban Udara

Indeks kelembaban udara di dalam Taman Sehatiselama tiga pekan pengukuran menunjukkan bahwa kriteria indeks pada kisaran agak kering dan Kering. Selanjutnya indeks kelembaban udara pada lokasi penelitian dapat dilihat pada Tabel 3.

Tabel 3. Rata-rata kelembaban udara dan Kriteria Indeks Kelembaban Udara di Taman Sehati

\begin{tabular}{clcccccl}
\hline \multirow{2}{*}{$\begin{array}{c}\text { Waktu pengambilan } \\
\text { Data }\end{array}$} & \multicolumn{3}{c}{ Kelembaban (\%) } & Kelembaban udara & Kriteria indeks \\
\cline { 3 - 4 } & & Pagi & Siang & Sore & & \\
\hline \multirow{2}{*}{ Minggu I } & Senin & 73 & 58 & 64 & 67 & Kering \\
\multirow{2}{*}{ Minggu II } & Minggu & 75 & 68 & 65 & 70,75 & Agak kering \\
\multirow{2}{*}{ Minggu III } & Senin & 70 & 74 & 65 & 69,75 & Kering \\
& Minggu & 81 & 73 & 63 & 74,5 & Agak kering \\
& Senin & 73 & 62 & 71 & 69,75 & Kering \\
& Minggu & 62 & 74 & 62 & 65 & Kering \\
\hline
\end{tabular}

Sumber: Data Primer, 2019

Pada Tabel 3 menujukan bahwa kelembaban udara tertinggi berada pada kelembaban $74,5 \%$ pada pengukuran minggu ke II pada hari minggu dengan 
kriteria indeks agak kering dan kelembaban udara rendah $65 \%$ pada pengukuran minggu ke III pada hari minggu dengan kriteria indeks kering. Penentuan kategori kering, agak kering, sedang, lembab dan basah mengacu pada indeks kelembaban udara.
3) Tingkat Kenyamanan termal

Suhu udara rata-rata, kelembaban udara dan Nilai THI yang berada di dalam RTH Taman Sehati dan di luar RTH Taman Sehati berdasarkan tingkat kerapatan vegetasi disajikan pada Tabel 4.

Tabel 4. Rata-Rata Suhu Udara, Kelembaban dan Tingkat Kenyamanan (Nilai THI) Berdasarkan Waktu Pengukuran Selama Tiga Minggu di Dalam RTH Taman Sehati

\begin{tabular}{lcccl}
\hline \multicolumn{1}{c}{ Waktu } & $\mathbf{T}\left({ }^{\circ} \mathbf{C}\right)$ & RH $(\%)$ & Nilai THI & Kriteria indeks \\
\hline Pagi & 25,1 & 73,3 & 23,7 & Nyaman \\
Siang & 29 & 66 & 27,02 & Tidak Nyaman \\
Sore & 28,0 & 73,0 & 26,5 & Sedang \\
\hline
\end{tabular}

Sumber: Data Primer, 2019

Pada Tabel 4 di atas menunjukan secara rata-rata suhu udara, kelembaban udara dan indeks kenyamanan di dalam RTH Taman Sehati berdasarkan waktu pengukuran selama 3 minggu bahwa kriteria Indeks THI, berada pada kriteria nyaman pada pagi hari dengan jumlah pengunjung yang ada setiap hari terutama pada hari libur. Pada siang hari nilai Indeks THI nya menjadi tidak nyaman. Nilai THI antara di dalam RTH dan di luar RTH Taman Sehati terjadi perbedaan pada setiap waktu pengukuran. Nilai THI pada hari Senin yang mewakili hari kerja di waktu pagi, siang dan sore hari ditunjukkan pada Gambar 1.

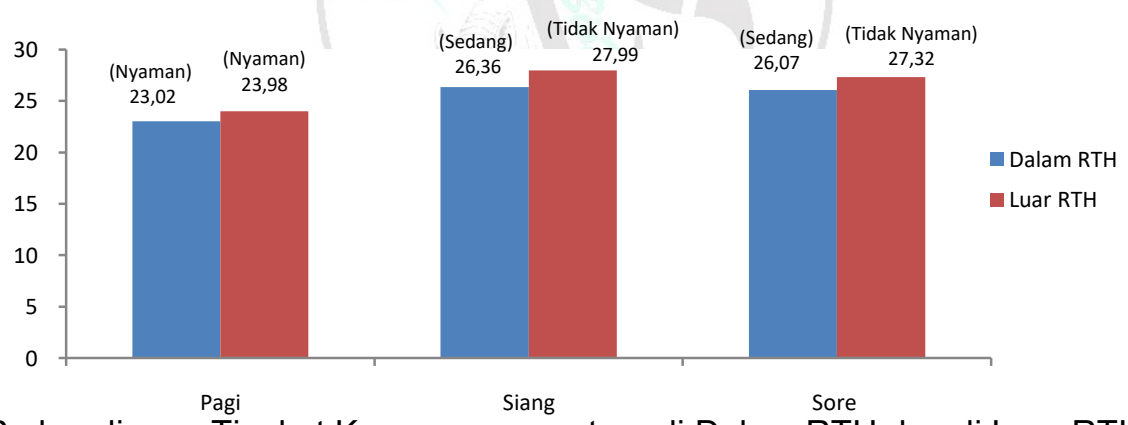

Gambar 1. Perbandingan Tingkat Kenyamanan antara di Dalam RTH dan di Luar RTH Taman Sehati pada hari senin (hari kerja)

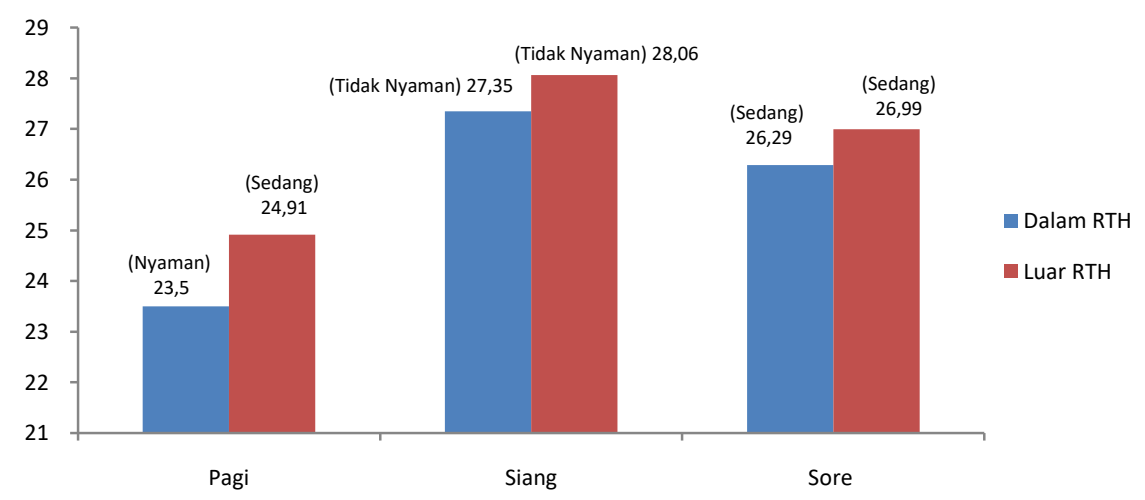

Gambar 2. Perbandingan Tingkat Kenyamanan antara di Dalam RTH dan di Luar RTH Taman Sehati pada Sabtu(Hari Libur) 


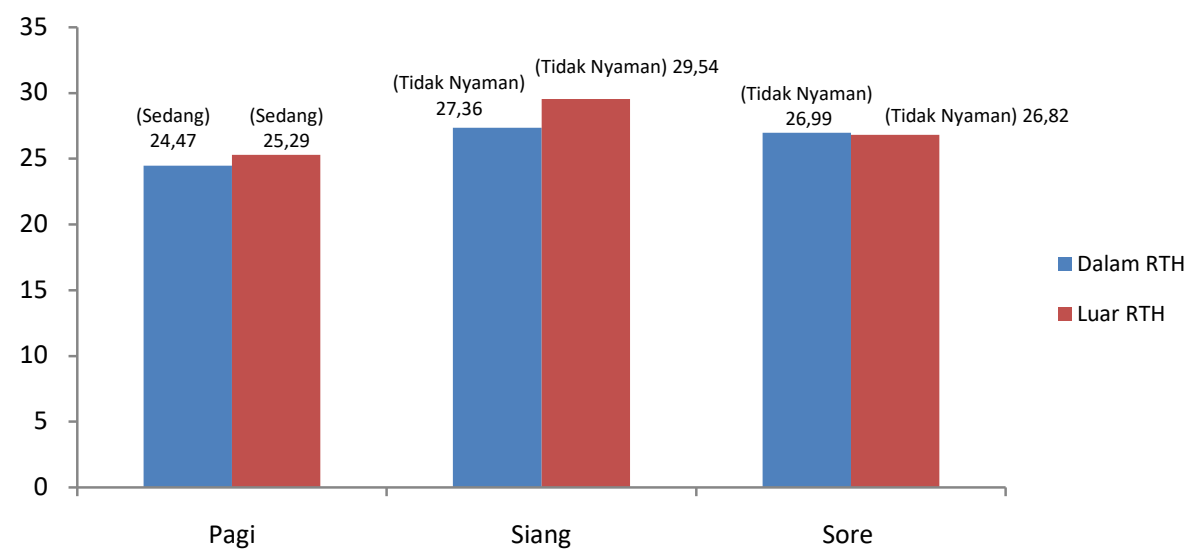

Gambar 3. Perbandingan Tingkat Kenyamanan antara di Dalam RTH dan di Luar RTH Taman Sehati pada Hari Minggu (Hari Libur)

Pada Gambar 1, 2, dan 3 tersebut menunjukkan bahwa indeks kenyamanan berdasarkan waktu dapat dilihat di dalam dan di luar Taman Sehati. Indeks kenyamanan di dalam Taman Sehati pada pagi hari nilai THI 23,02 (kriteria indeks nyaman), pada siang hari dengan nilai THI 26,36 (kriteria indeks sedang) dan pada sore hari dengan nilai THI 26,07 (kriteria indeks sedang). Namun pada nilai THI yang berda di luar Taman Sehati pada pagi hari dengan nilai $\mathrm{THI}$ sebesar 23,98 (kriteria indeks nyaman), pada siang hari nilai THI 27,99 (kriteria indeks tidak nyaman) dan pada sore hari nilai $\mathrm{THI}$ mencapai 27,32 (kriteria indeks tidak nyaman). Dapat dikatakan bahwa waktu berkunjung di dalam Taman Sehati pada pagi hari dengan kategori nyaman, siang dan sore hari kategori sedang, sedangkan di luar Taman Sehati pada pagi hari kategori nyaman, siang dan sore hari kategori tidak nyaman.

\section{Ruang Terbuka Hijau dan Vegetasi yang berada di Taman Kota}

Vegetasi atau pohon yang berada di Taman Sehati memiliki struktur ruang dengan pola sebaran mengelompok, memanjang dan tersebar pada kawasan taman. Pohon sangat erat kaitanya dengan iklim mikro pada suatu daerah. Pohon peneduh yang terdapat di RTH
Taman Sehati yaitu jenis tanaman Tanjung dan Trambesi. Serta penambah kerimbunan dan keunikan warna menjadikan ini tanaman hias dan juga biasanya sebagai tanaman yang berfungsi sebagai pagar yaitu Puncuk Merah. Pohon penyerap polusi udara yang terdapat di Taman Sehati yaitu jenis tanaman palem, pohon peredam kebisingan yang terdapat di Taman Sehati yaitu jenis tanaman tanjung dan jenis tanaman paling efektif dalam mengurangi efek pemanasan akibat radiasi matahari atau mampu menyerap karbondioksida yaitu Trambesi.

Kurangnya vegetasi tentunya akan memberikan efek terhadap suhu udara serta kelembaban udara pada suatu kawasan. Vegetasi yang tidak terlalu banyak vegetasinya tentunya akan memberikan suhu meningkat. Tingginya suhu udara dan kelembaban udara akan berdampak terhadap kenyamanan suatu kawasan (Gucci et al., 2016).

\section{Tingkat Kenyamanan}

Berdasarkan hasil pengukuran rata-rata suhu udara dan kelembaban udara yang dilakukan selama 3 minggu di Taman Sehati, menunjukan terjadinya perbedaan dimana pada minggu pertama baik pada hari senin maupun hari Minggu menunjukan kriteria indeks agak panas. 
Namun pada mengukuran minggu kedua dan ketiga menunjukklan kriteria indeks sejuk. Hal ini menunjukkan bahwa pengaruh atmosfir dan meterologi dilokasi tersebut mempengaruhi keberadaan kondisi iklim mikro yang ada. Selain itu struktur pohon juga berpengaruh terhadap iklim mikro pada suatu taman. Apabila disuatu taman di dominasi oleh tegakan pohon maka iklim mikro yang ada jauh lebih sejuk dibanding dengan semak. Perbedaan ini terjadi dalam kemampuan menyerap radiasi matahari, naungan dan melakukan transpirasi.

Struktur pohon memiliki kemampuan dalam menyerap radiasi matahari, memberikan nauangan, dan melakukan transpirasi sehingga dapat menurunkan suhu udara dan meningkatkan kelembaban udara. Namun, karena ukuran semak lebih kecil dari pada pohon maka kemampuannya dalam menurunkan suhu udara dan meningkatkan kelembaban udara tidak semaksimal pohon (Brown \& Gillespie, 1995). Semak juga memiliki pengaruh terhadap angin, hanya saja dalam skala lebih kecil dari pohon. Semak sama seperti pohon, terdapat beberapa karakteristik struktural semak yang dapat mempengaruhi iklim mikro diantaranya: bentuk tajuk, penanaman, ukuran tanaman, dan kepadatan tajuk (Scudo, 2002). Semak dengan tajuk piramidal dan bulat, ditanam berjejer/berkelompok, memiliki tinggi yang sedang (1-2 meter), serta memiliki kepadatan tajuk tinggi dapat menurunkan suhu udara dan meningkatkan kelembaban udara. Sementara itu, semak dengan tajuk kolumnar/horisontal; ditanam secara tunggal; memiliki ukuran sangat rendah, rendah, atau tinggi (0,5-1 dan 2-3 meter); serta memilik kepadatan tajuk rendah sampai sedang memiliki kemampuan untuk meningkatkan suhu udara dan menurunkan kelembaban udara. Selain berpengaruh dalam suhu udara dan kelembaban udara sama seperti halnya pohon, semak juga berpengaruh terhadap angin. Semak memiliki fungsi untuk mengarahkan angin, menyimpan, menghalangi, maupun menyaring angin. Bentuk tajuk pohon dan jarak tanamnya juga mempengaruhi dalam mengarahkan angin. Pohon yang memiliki bentuk tajuk kolumnar, piramidal, atau bulat; ditanam berjejer/berkelompok meloloskan angin lebih banyak. Selanjutnya, menurut Immaculata dkk., (2017) bahwa kerapatan vegetasi berpengaruh terhadap suhu dan tingkat kenyamanan. Vegetasi denga tajuk yang rapat memiliki suhu rata-rata lebih rendah dan kelembaban udara rata-rata lebih tinggi bila dibandingkan pada lokasi RTH dengan tajuk pohon yang jarang.

Perbedaan suhu, kelembaban dan tingkat kenyamanan di dalam RTH Taman sehati sengat dipengaruhi oleh ketebalan kanopi yang dimiliki. Vegetasi pohon yang memiliki kanopi yang tebal maka suhu udara semakin sejuk. Menurut Effendi dan Aprihatmoko (2014) penutupan kanopi pepohonan akan memberikan naungan yang berfungsi menghalangi sinar matahari dan mereduksi suhu udara sehingga udara menjadi sejuk. Kaitannya dengan kenyamanan diungkapkan Hayati (2013) yaitu kondisi kerapatan tinggi akan mempengaruhi iklim mikro dan menentukan kenyamanan lingkungan. Hadi (2012) menyatakan bahwa adanya tanaman dalam RTH membuat lingkungan lebih nyaman karena dapat memodifikasi iklim mikro. Krisdianto (2012) juga berpendapat bahwa pepohonan berperan dalam menjaga kenyamanan lingkungan perkotaan.

Tingkat kenyamanan rata-rata yang di Taman Sehati yang dihitung berdasarkan nilai Indeks THI dari nilai temperatur dan kelembaban relatif Wirasasmita (2003) menunjukan bahwa pada pagi hari tergolong nyaman sedangkan siang hari dan sore hari tergolong sedang. Kualitas RTH umumnya 
berkaitan dengan banyakknya jumlah pohon yang rindang, semakin banyak jumlah pohon yang rindang maka semakin baik kondisi RTH.

Nilai THI rata-rata di Taman Kota pada pengukuran Minggu I pada hari senin nilai $\mathrm{THI} 25,95$ dan pada hari minggu nilai $\mathrm{THI}$ 25,79. Pengukuran minggu II pada hari senin nilai THI 25,43 dan pada hari minggu nilai $\mathrm{THI} 25,74$. Titik pengukuran minggu III pada hari senin nilai THI 24,89 dan pada hari minggu nilai THI 25,15.

Tyahyono (2004), menyatakan suhu merupakan faktor iklim yang mempengaruhi kenyamanan manusia. Suhu terlalu tinggi atau rendah akan menggangu kegiatan manusia. Pada lokasi yang memiliki vegetasi rumput, keadaan udara relatif lebih kering karena kapasitas udara untuk menampung air semakin tinggi seiring dengan naiknya suhu udara.

Selanjutnya, nilai suhu udara dan kelembaban udara di Taman Sehati dikelompokkan menjadi dua yaitu pengukuran di dalam Taman Sehati dan pengukuran di luar Taman Sehati dengan pengukuran 3 titik sesuai dengan tingkat kerapatan pohon, yaitu tingkat kerapatan tinggi, tingkat kerapatan sedang dan tingkat kerapatan rendah ketinggian pengukuran 2 meter di atas permukaan tanah yang diperoleh nilai rata-rata suhu udara dan kelembaban udara. Kemudian di pengukuran di luar Taman Sehati sebagai pembanding.

\begin{tabular}{ccc}
\multicolumn{2}{c}{ Pengukuran suhu udara, } \\
kelembaban udara dan indeks \\
kenyamanan di dalam
\end{tabular} dilakukan dengan pengukuran kerapatan pohon. Titik pengukuran I kerapatan tinggi suhu udara $26,37^{\circ} \mathrm{C}$, kelembaban udara $68,75 \%$ dengan nilai THI 24,72. Titik pengukuran II kerapatan pohon sedang suhu udara $26,67^{\circ} \mathrm{C}$, kelembaban udara $71,75 \%$ dan nilai THI 25,16. Titik pengukuran III kerapatan rendah sehu udara $27,27^{\circ} \mathrm{C}$, kelembaban udara $73,75 \%$ dan nilai THI 25,83. Hal ini membuktikan bahwa pohon dengan kerapatan tinggi memiliki suhu lebih rendah dibandingkan dengan pohon yang memiliki kerapatan rendah. Perbedaan karakteristik masing-masing jenis vegetasi dalam menyerap ataupun memantulkan energi matahari yang diterimanya. Kondisi vegetasi dengan kerapatan pohon yang tinggi dan luas penutupan lahan akan mempengaruhi kondisi iklim mikro (Saputro et al., 2010).

Pengukuran di luar Taman Kota, titik pengukuran I kerapatan pohon tinggi suhu udara $27,22^{\circ} \mathrm{C}$, kelembaban udara $74 \%$ dan nilai THI 25,80. Titik pengukuran II kerapatan pohon sedang suhu udara $28,02^{\circ} \mathrm{C}$, kelembaban udara $68,5 \%$ dan nilai THI 26,25. Titik pengukuran III kerapatan pohon rendah suhu udara $28,4^{\circ} \mathrm{C}$, kelembaban udara $73 \%$ dan nilai THI 26,86.

Perbandingan suhu udara, kelembaban udara dan indeks kenyamanan di dalam dan di luar Taman Kota, suhu udara di luar lebih tinggi dibandingkan dengan suhu udara yang berada di dalam Taman Kota dengan hal ini tingkat kenyamanan di dalam Taman Kota lebih nyaman dibandingkan dengan di luar Taman Sehati. Vegetasi yang berada di luar Taman Sehati lebih sedikit bila dibandingkan dengan di dalam Taman Sehati. Menurut Lakitan (2002), kondisi vegetasi RTH menyebabkan terjadinya peningkatan suhu, suhu vegetasi di atas permukaan terbuka akan lebih tinggi bila dibandingkan dengan dengan suhu di bawah naungan karena radiasi matahari yang diterima oleh tanaman tidak dipantulkan kembali.

Pengukuran di luar Taman Kota berdasarkan waktu yang diperoleh pada pagi hari nilai $\mathrm{THI} 23,98$ dengan kriteria indeks nyaman, pada siang hari nilai THI 27,99 dengan kriteria indeks tidak nyaman dan pada sore hari nilai THI 27,32 dengan 
kriteria indeks tidak nyaman. Waktu berkunjung di Taman Sehati pada pagi hari dengan kriteria nyaman, siang dan sore hari dengan kriteria indeks tidak nyaman.

\section{KESIMPULAN}

Kesimpulan dari penelitian ini yaitu manfaat Taman Sehati terhadap. Tingkat kenyamanan rata-rata dalam kawasan Taman Sehati pada pengukuran selama 3 minggu berada pada kriteria nyaman pada pagi hari dengan jumlah pengunjung yang ada setiap hari terutama pada hari libur. Pada siang hari nilai Indeks THI-nya menjadi tidak nyaman dan sore hari berada pada kriteria sedang.

\section{SARAN}

Saran penulis dalam penelitian ini yaitu dapat di lihat sebagai berikut:

1. Vegetasi yang ada di Taman Sehati masih kurang, sehingga jenis dan jumlah vegetasi lebih diperbanyak sehingga indeks kenyamanan di Taman Sehati lebih nyaman mulai dari pagi sampai sore hari.

2. Perlu penambahan jenis vegetasi yang memiliki kanopi yang tebal dan lebar di dalam RTH Taman Sehati.

\section{DAFTAR PUSTAKA}

Arifin, H. Susilo. 1991. Buku Kenangan Lomba Taman Tingkat Nasional II 1991. Semarang. Biro Kependudukan dan Lingkungan Hidup Jawa Tengah.

Badan Pusat Statistik, Kabupaten Banggai dalam Angka 2018.

Choirunnisa, B. 2016. Tingkat Kenyamanan di Berbagai Taman Kota di Bandar Lampung. Universitas Lampung. Bandar Lampung.

Dahlan, E.N. 1992. Hutan Kota untuk Penggelolaan dan Peningkatan Kualitas Lingkungan Hidup.
Buku. Asosiasi Pengusaha Hutan Indonesia. Jakarta.92 p.

Danarti, K. 2011. Peran Taman Balekambang sebagai Pembentuk Estetika Kota. Jurnal Teknik dan Arsitektur FT UTP Vol 9.

Efendie, U. 2017. Fungsi Ekologi Taman Kota. Jurnal Asia. http://www.jurnalasia.com/opini/m enyoal-fungsi-ekologis-tamankotal

Gucci, M.P.R., Zulkarnaini dan S. Anita. 2016. Analisis Perbedaan Iklim Mikro Terhadap Kenyamanan Pengunjung pada Ruang Terbuka Hijau di Kota Pekanbaru. Jurnal IImu Lingkungan. 1(-)

Hadi, R. 2012. Evaluasi indeks kenyamanan taman kota (Lapangan Puputan Badung I Gusti Ngurah Made Agung Denpasar, Bali. E-Jurnal Agroekoteknologi Tropika V. 1(1): (34- 45).

Hayati, J., Santun, R.P. dan Siti, N. 2013. Pengembangan ruang terbuka hijau dengan pendekatan kota hijau di Kota Kandangan. Jurnal Tata Loka. 15 (4): 306-316

Immaculata M.D. Sulistyana, S.B. Yuwono dan Rusita 2017. Kenyamanan Hutan Kota Linara Berbasis Kerapatan Vegetasi, Iklim Mikro dan Persepsi Masyarakat di Kota Metro, Lampung, Jurnal Silva Lestari. Vol. 5 No. 2

Irwan, Z. D. 2007. Prinsip-prinsip Ekologi: Ekosistem Lingkungan dan Pelestarian. Jakarta: Bumi Aksara.

Krisdianto, Soemarno, Udiansyah, Januwiadi, B. dan Rhamadani $F$. 2012. Potensi vegetasi tusam menjadi payung hijau di RTHKP Kota Banjarbaru. Jurnal Lingkungan Binaan Indonesia. 1 (1) : 19-26.

Lakitan. 2002. Pengaruh Ketersediaan Ruang Terbuka Hijau Terhadap Iklim Mikro di Makassar. Universitas Hasanuddin Makassar. 
Mulyandari, H. 2010. Pengantar Arsitektur Kota. Andi Yogjakarta.

Nieuwolt, S. 1977. Tropical Climatology. London. Wiley.

Peraturan Menteri Dalam Negeri Nomor 1 Tahun 2007 Tentang Penataan Ruang Terbuka Hijau Kawasan Perkotaan.

Peraturan Menteri Pekerjaan Umum No: 05/PRT/M/2008 Tentang Pedoman Penyediaan dan Pemanfaatan Ruang Terbuka Hijau di Kawasan Perkotaan.

Purnomohadi, Ning. 2006. Ruang Terbuka Hijau Sebagai Unsur Utama Tata Ruang Kota. Direktorat Jenderal Penataan Ruang, Departemen Pekerjaan Umum. Jakarta.

Rakhman, D.R. 2012. Kajian Rancangan Masterplan Ruang Terbuka Hijau Kota Bogor [Tesis]. Universitas Indonesia.

Saputro, T.D., S.F. Indung dan S. Bambang. 2010. Studi Pengaruh Area Perkerasan Terhadap Perubahan Suhu Udara. Jurnal Lanskap Indonesia. 2(2): 76-82.
Solecki, W.D dan J.M. Welch. 1995. Urban parks green parks or green walls. Journal Landscape and Urban Planning. 32 : 93-106.

Tyahyono, B. 2004. Pengendalian Hutan Kota dalam Pengendalian Iklim Kota. Jurnal RUAS. 11(1) : 334347.

Undang-Undang Republik Indonesia Nomor 26 Tahun 2007 Tentang Penataan Ruang.

Wahida, N., A. Renni dan M. Isya. 2018. Perencanaan Kebutuhan Ruang Terbuka Hijau Parkir di Kawasan Taman Sari Kota Banda Aceh. Jurnal Arsip Rekayasa Sipil dan Perencanaan (JARSP). Universitas Syiah Kuala, Banda Aceh.

Wirasasmita, M. 2003. Aplikasi Iklim Terhadap Perkembangan Urban, Metropolita Bandung [Buku]. Pusat Pemanfaatan Sains Atmosfer dan Iklim. LAPAN. Bandung. 